\title{
Advances in Logic, Operations and Computational Mathematics
}

\section{Alireza Heidari*}

Faculty of Chemistry, California South University, 14731 Comet St. Irvine, CA 92604, USA

*Corresponding author: Alireza Heidari, Faculty of Chemistry, California South University (CSU), 14731 Comet St. Irvine, CA 92604, USA, Tel: 1-775-410-4974; E-mail: Scholar.Researcher.Scientist@gmail.com

Received date: October 24, 2016, Accepted date: October 24, 2016, Published date: October 24, 2016

Copyright: (C) 2016 Heidari A. This is an open-access article distributed under the terms of the Creative Commons Attribution License, which permits unrestricted use, distribution, and reproduction in any medium, provided the original author and source are credited.

\section{Editor's Note}

Journal of Applied \& Computational Mathematics Volume 5, Issue 2 comprised of 7 research articles and 4 opinion articles and are focused on the innovation of polygon, Euler, linear and non-linear equations.

EL-Kholy et al., in their research article discussed about balanced folding over a polygon and Euler numbers. The study proved that for a balanced folding of a simply connected surface $\mathrm{M}$, there is a subgroup of the group which is called all homeomorphisms of $\mathrm{M}$ that will acts 1transitively on the 2-cells of M [1].

Gil et al., in their research have reported about the exponentially stabile non-linear, non-autonomous multivariable discrete systems. Based on the recent estimates on matrix equations, the findings suggest that a class of non-autonomous discrete-time systems is governed by semi-linear vector difference equations along with slowly varying linear parts [2].

Author Shahooth et al., aimed to study the present numerical methods for solving the linear Volterra-Fredholmintegro-differential equations of the second kind. The study concluded that experimented technique transforms the integro-differential equations to the system of algebraic equations and in order to illustrate the efficiency and accuracy of this method some numerical results are presented [3].
Atteya in his opinion article presented the properties of Lie Algebras, with respect to traditional usage and present status. This well-established theory could enhance the applicability of the lie algebras [4].

Hungarian author Faragó study, envisaged about Sequence Acceleration. The Study concluded that Aitken's and Steffensen's methods can accelerate the speed of the convergence of $s$ the fixed sequences by transforming this sequence. The Richardson's method also upholds the validity of the two sequences method [5].

\section{References}

1. EL-Kholy E, El-Sharkawey E (2016) Balanced Folding Over a Polygon and Euler Numbers. J Appl Computat Math 5: 296.

2. Gil M (2016) Exponential Stability of Nonlinear Nonautonomous Multivariable Discrete Systems. J Appl Computat Math 5: 297.

3. Shahooth MK, Ahmad R, Salma U, Swidan W, Al-Husseini OK, et al. (2016) Approximation Solution to Solving Linear Volterra-Fredholm Integro-Differential Equations of the Second Kind by Using Bernstein Polynomials Method. J Appl Computat Math 5: 298.

4. Atteya MJ (2016) Some Properties of Lie Algebras. J Appl Computat Math 5: 300 .

5. Faragó I (2016) Some Notes on the Sequence Acceleration. J Appl Computat Math 5: 303. 